\title{
When Do Motivational Factors Lead to Negative User Experience on Social Networking Applications?
}

\section{Shin-Yi Huang}

National Taiwan University of Science and Technology

Miles M. Yang

Macquarie University

miles.yang@mgsm.edu.au

\section{Chien-Hsiung Chen}

National Taiwan University of Science and Technology

\section{Abstract}

We investigate why some innovative user interface (UI) designs (e.g., Facebook Home), although initially expected to encourage users to accept or adopt social networking applications (apps), actually discouraged users from using those applications over time. Using two experimental studies, we explore the relationship between new design factors and user behavioural intentions. In Study 1, we adopted two-factor theory to discover motivational factors related to using a social networking app. We then designed and created a virtual social networking app (called Unicorn) using these identified motivational factors. In Study 2, we investigated how motivational factors de-motivate user behavioural intentions. We unpacked this relationship using the Technology Acceptance Model (TAM). Further, we explored how involvement level may alleviate this negative relationship. Our results show that users with a high involvement level exhibit a relatively high level of perceived usefulness and perceived playfulness. Therefore, involvement level can alleviate the negative relationship that exists between motivational factors and behavioural intentions. This study provides both theoretical implications to the literature and practical insights for UI designers.

Keywords: Social networking applications, Technology Acceptance Model, two-factor theory, involvement level, Facebook

\section{Introduction}

One of the critical challenges for user interface (UI) designers has been the question of how to create a desirable UI that can both attract and retain users (Chou, Lai, \& Liu, 2013; Kim, Kim, \& Han, 2013; Mouakket, 2015; Park, Roman, Lee, \& Chung, 2009; Wang, 2016). A new, innovative UI for social networking apps may have a better opportunity of attracting user attention and subsequently increase the rate of revisiting. However, some innovative designs fail to achieve these desired results over the long term-even though, initially, those same designs received considerable attention from users. Indeed, over time, some new designs produce the opposite effect from that intended, actually discouraging users from adopting or accepting the renovated application. The Facebook Home app is an example of a new, disruptive and innovative design that failed to succeed in attracting users to that application due to its UI design and functionality (Carlson, 2013).

In 2013, Taiwanese smartphone and tablet manufacturer HTC allied with Facebook to launch a new mobile app named Facebook Home on their Android mobile phone, the HTC First. The goal was to create a strong connection between mobile devices and Facebook by providing a 
drop-in replacement for the existing home screen ("launcher") on an Android device (Pogue, 2013). At the time, industry experts noted that Facebook Home's new function in its UI design, which allows users to place their Facebook friends in front of their phone's home screen directly, results in other apps fading into the background (Stern, 2013). This new function is highly appreciated, according to IT experts (Pogue, 2013). However, upon Facebook Home's launch, the feedback from users was overwhelmingly negative, especially this new function (Cheng, 2013). The app's poor reception was evidenced by the fact that within a few hours after its release, Facebook Home received an average rating of 2.3 out of 5 stars on Google Play (Grove, 2013). A business case like this provokes an interesting question: Why is it that some innovative UI designs or functions counterintuitively demotivate users' behavioural intentions?

Recently, researchers have begun to study why people reuse social networking services (SNS) through the research lens of various perspectives such as socio-technical systems (Chai \& Kim, 2012) and social influence theory (e.g., Lin \& Lu, 2015; Tao, 2011) (and see a review of relevant work in the next section). Using two experimental studies, we investigate this question from an organisational psychology perspective, using two-factor theory, the Technology Acceptance Model (TAM), and involvement theory (IL). In Study 1, we adopted two-factor theory to discover motivational factors related to using a social networking app. We then designed and created a virtual social networking app using the identified motivational factors. In Study 2, we investigated how motivational factors de-motivate user behavioural intentions. We advance our understanding of SNS app UI designs and provide new insights into how and why some innovative designs fail to attract and retain users.

\section{Literature Review and Theoretical Development}

Our study focuses on how UI design on functionalities encourage or discourage use of SNS apps. Next, we discuss the relevant work, and then in the following section we introduce the theoretical background of our work by introducing two-factor theory, followed by involvement theory and TAM.

Recently, researchers have begun to study why people reuse social network sites (SNSs) through the research lenses of social influence theory ( $\operatorname{Lin} \& \mathrm{Lu}, 2015$; Tao, 2011), social networking theory (Luarn \& Chiu, 2015), the technology acceptance model (Rauniar, Rawski, Yang, \& Johnson, 2014), gratifications theory (Wei \& Lu, 2014), social cognitive theory (Chiang \& Hsiao, 2015), and innovation diffusion theory (Chiang, 2013). Table 1 summarises prior related studies from 2012 to 2016, showing that the use and design of SNSs has received considerable attention. In particular, research using gratifications theory and innovation diffusion theory has explained why people employ continuous use of SNSs (Chiang, 2013). They found that attitude toward SNSs had the strongest main effect on continuous intention, while the impact of social norms has no effect on the different stages of the innovation diffusion process. However, to the best of our knowledge, there are limited studies investigating the continuous use of SNS apps.

Our study differs from prior studies in three ways. First, we are interested in SNS apps which have received little attention thus far (Hacker, Wickramasinghe, \& Durst, 2017; Wang, 2016). Second, in order to understand the actual impact of design factors (Nguyen, Johnson, \& Hackett, 2003), we not only conducted a traditional survey to find out the critical design factors, we also implemented those important factors in a virtual, new SNS app called 


\begin{tabular}{|c|c|c|c|}
\hline $\begin{array}{l}\text { Study } \\
\text { (Year) }\end{array}$ & Base-line theory & Target online services/samples & Key Findings \\
\hline Tao (2011) & $\begin{array}{l}\text { Social influence } \\
\text { theory }\end{array}$ & $\begin{array}{l}\text { Data were collected from } 450 \text { students in } \\
\text { China. All participants had to complete } \\
\text { the survey questionnaire based on their } \\
\text { favourite online community usage } \\
\text { experience. }\end{array}$ & $\begin{array}{l}\text { The results show that both social identity and group norms have significant } \\
\text { effects on user participation. In addition, group norms affect social identity. It } \\
\text { was not possible to find the effect of subjective norms on participation } \\
\text { intention. }\end{array}$ \\
\hline $\begin{array}{l}\text { Chai and } \\
\text { Kim } \\
(2012)\end{array}$ & $\begin{array}{l}\text { Socio-technical } \\
\text { system }\end{array}$ & $\begin{array}{l}\text { Data were collected from } 211 \text { SNSs users } \\
\text { at a large university in the U.S. }\end{array}$ & $\begin{array}{l}\text { This study investigated the factors which influence knowledge contribution } \\
\text { behaviours of SNS users by sharing through user-created contents with one } \\
\text { another. This study discussed the roles of social system factors, such as } \\
\text { ethical culture, social ties, and a sense of belonging in online social network. } \\
\text { Further, this study examined technical systems factors, such as structural } \\
\text { assurance of service providers and structural assurance of the Internet. }\end{array}$ \\
\hline $\begin{array}{l}\text { Chiang } \\
(2013)\end{array}$ & $\begin{array}{l}\text { Gratification } \\
\text { theory, innovation } \\
\text { diffusion theory }\end{array}$ & $\begin{array}{l}\text { Data were collected from } 348 \text { members } \\
\text { of Facebook in Taiwan, using an online } \\
\text { questionnaire. }\end{array}$ & $\begin{array}{l}\text { The study investigates how innovation diffusion perspective and uses and } \\
\text { gratifications perspective influence the continuous use of SNSs. In particular, } \\
\text { attitude toward SNSs had the strongest direct effect on continuous intention, } \\
\text { while the impact of social norms was not significant in the different } \\
\text { innovation diffusion stages. }\end{array}$ \\
\hline $\begin{array}{l}\text { Wei and } \\
\text { Lu (2014) }\end{array}$ & $\begin{array}{l}\text { Network } \\
\text { externalities theory, } \\
\text { gratification theory }\end{array}$ & $\begin{array}{l}\text { Data were collected from } 237 \text { students } \\
\text { and office workers who were using } \\
\text { Bahamut (www.gamer.com.tw), } \\
\text { Gamebase (www.gamebase.com.tw), } \\
\text { and Taiwan's game-related bulletin } \\
\text { board systems. }\end{array}$ & $\begin{array}{l}\text { The results reveal that both network externalities and individual } \\
\text { gratifications significantly influence the intention to play social games on } \\
\text { mobile devices. Time flexibility, however, which is one of the mobile device } \\
\text { features, appears to contribute relatively little to the intention to play mobile } \\
\text { social games. }\end{array}$ \\
\hline $\begin{array}{l}\text { Rauniar et } \\
\text { al. (2014) }\end{array}$ & $\begin{array}{l}\text { Technology } \\
\text { acceptance model }\end{array}$ & $\begin{array}{l}\text { Data were collected from } 389 \text { full-time } \\
\text { students from two business schools in } \\
\text { the USA. }\end{array}$ & $\begin{array}{l}\text { The results demonstrate that the revised social media TAM model proposed } \\
\text { in this study supports all the hypotheses of social media usage behaviour. } \\
\text { The results of this study provide evidence for the importance of additional } \\
\text { key variables to TAM in considering user engagement on social media sites } \\
\text { and other social-media-related business strategies. }\end{array}$ \\
\hline
\end{tabular}




\begin{tabular}{|c|c|c|c|}
\hline $\begin{array}{l}\text { Study } \\
\text { (Year) }\end{array}$ & Base-line theory & Target online services/samples & Key Findings \\
\hline $\begin{array}{l}\text { Chiang } \\
\text { and Hsiao } \\
(2015)\end{array}$ & $\begin{array}{l}\text { Gratification } \\
\text { theory, } \\
\text { social cognitive } \\
\text { theory }\end{array}$ & $\begin{array}{l}\text { Data were collected from } 265 \text { students } \\
\text { and office workers who were mostly } \\
\text { from Taiwan, with a few from Hong } \\
\text { Kong and China. }\end{array}$ & $\begin{array}{l}\text { The results indicated that continuance motivation and sharing behaviour } \\
\text { were important antecedents of YouTube 'stickiness' and mediated the } \\
\text { influence of need, personal and environmental factors. }\end{array}$ \\
\hline $\begin{array}{l}\text { Lin and } \\
\text { Lu (2015) }\end{array}$ & $\begin{array}{l}\text { Social influence } \\
\text { theory }\end{array}$ & $\begin{array}{l}\text { Data were collected from } 116 \text { students } \\
\text { and office workers who were using or } \\
\text { had used mobile SNS services in } \\
\text { Taiwan. }\end{array}$ & $\begin{array}{l}\text { The results revealed that mobile convenience, service compatibility, security } \\
\text { risk and cognitive effort have a significant and indirect impact on the user } \\
\text { acceptance of mobile SNSs through their respective paths on hedonic value } \\
\text { and utility value. }\end{array}$ \\
\hline $\begin{array}{l}\text { Luarn } \\
\text { and Chiu } \\
(2015)\end{array}$ & $\begin{array}{l}\text { Social network } \\
\text { theory }\end{array}$ & $\begin{array}{l}\text { Data were collected from } 145 \\
\text { undergraduates who had using } \\
\text { Facebook experience. }\end{array}$ & $\begin{array}{l}\text { The results developed an algorithm (predictive model) that quantifies and } \\
\text { measures tie strength continuously to bridge the gap between theory and } \\
\text { practice. The results found that the variables in the dimension of emotional } \\
\text { intensity had stronger effects than other interaction variables. }\end{array}$ \\
\hline $\begin{array}{l}\operatorname{Lim} \\
(2015)\end{array}$ & Gratification theory & $\begin{array}{l}\text { The study tests } 320 \text { usable responses } \\
\text { collected from e-shoppers against the } \\
\text { integrated model using structural } \\
\text { equation modelling. }\end{array}$ & $\begin{array}{l}\text { The findings show the significance of perceived value, social factors, } \\
\text { perceived ease of use, perceived usefulness, entertainment gratification, web } \\
\text { irritation, emotional state, and web atmospherics in the process of e- } \\
\text { shopping. }\end{array}$ \\
\hline $\begin{array}{l}\text { Lin and } \\
\mathrm{Lu}(2015)\end{array}$ & $\begin{array}{l}\text { Social influence } \\
\text { theory }\end{array}$ & $\begin{array}{l}\text { Data were collected from } 116 \text { students } \\
\text { and office workers who were using or } \\
\text { had used mobile SNS services in } \\
\text { Taiwan. }\end{array}$ & $\begin{array}{l}\text { The results revealed that mobile convenience, service compatibility, security } \\
\text { risk and cognitive effort have a significant and indirect impact on the user } \\
\text { acceptance of mobile SNSs through their respective paths on hedonic value } \\
\text { and utility value. }\end{array}$ \\
\hline
\end{tabular}

Table 1. Selected empirical studies related to SNS from 2012 to 2015 
'Unicorn' in order to discover the actual impact of such factors. Third, we examine the relationship between design factors and adoption/acceptance of SNS apps using three baseline theories: Herzberg's two-factor theory, involvement theory and TAM, which provides us with a solid understanding of user behaviours from an organisational psychology perspective. We selected these three baseline theories due to our summary of the current literature in Table 1. Particularly, it delivers three key messages. First, it shows motivation play an important role in users' adoption/acceptance of SNS apps (i.e., Tao (2011), Chiang (2013), Chiang \& Hsiao (2015)). Thus, we consider Herzberg's two-factor theory in our study (see Section 2.1). Second, recent studies such as Luarn and Chiu (2015), and Chai and Kim (2012) implicitly show that users' perceived level of interests in using a SNS app has significant impact on their adoption attitude. Therefore, we consider involvement theory (see Section 2.2) in developing our hypotheses. Third, TAM (see Section 2.3) is often utilized as mediators for examining the relationship between web design and users' behaviours. Relevant studies in Table1 include Lim (2015), Lin and Lu (2015), Wei and Lu (2014), and Rauniar et al. (2014).

\subsection{Two-factor theory}

Herzberg's (1959) two-factor theory shows that neither satisfaction nor dissatisfaction are impervious to change, and that the development of either state is influenced by two primary components: hygiene factors (HFs) and motivational factors (MFs). HFs refer to the basic elements that quantify one's satisfaction, including aspects of the general task environment involved. When lacking HFs, individuals demonstrate high dissatisfaction. In contrast, MFs refer to the characteristics of the work itself, such as challenges and a sense of fulfilment and personal growth that stimulate individuals' satisfaction regarding their task environment. While the presence of MFs is sufficient to motivate individuals, those factors, however, have little or no effect on one's dissatisfaction (Herzberg, 1987).

This dual nature of motivation theory has attracted a great deal of attention from researchers. Subsequent studies have continually supported the two-factor model (Maidani, 1991; Murphy \& Fraser, 1978; Schwab \& Cummings, 1970; Soliman, 1970; Whitsett \& Winslow, 1967). Consequently, two-factor theory promotes the idea of job redesign in order to increase the quality of work performance and individuals' satisfaction levels (Hackman \& Oldham, 1975; Kopelman, 1986). The theory has been widely used by practitioners and managers to build MFs into the work environment (Rantz, Scott, \& Porter, 1996).

Further research into the two-factor theory in organisational psychology has shown that the theory can be applied to 'motivation' in other disciplines and research areas, such as education (Poppleton, 1988), consumer motivation (Maddox, 1981; Tuten \& August, 1998) and knowledge sharing (Hendriks, 1999). In particular, the two-factor theory has been applied to understanding users' motivation for using Web services. For example, Zhang and von Dran (2000) argue that HFs are critical to ensuring that websites are functional, whereas MFs can contribute to users' satisfaction levels by adding value to websites. A follow-up study by $\mathrm{Wu}$, Chuang and Chen (2008) shows that, in an application of search engine websites, while HFs (e.g., basic query process) provide general and functional operations and reliable service, MFs add value to applications of search engine websites in order to enhance consumer satisfaction. For example, search engine developers need to provide stability in a search engine as a HF to support users in their information seeking process. Moreover, search engine developers can provide a ranking function (e.g., the degree that the relevance ranking of search results meets user needs) to increase user satisfaction levels by helping users navigate and comprehend the 
retrieved information. While the use of two-factor theory provides insights to website development (Chuang \& Chen, 2008), online software services (Lee, Chae, \& Cho, 2013), and mobile data services (Lee, Shin, \& Lee, 2009), these insights receive less attention in the development of SNS applications.

Following this line of research, in the present work we adopted two-factor theory to investigate users' potential needs in using SNS app UIs in Study 1. Then we examined the effects of MFs on SNS users' behavioural intentions (BI) in Study 2. Prior research suggests that, when designing websites, interface designers should use HFs as prerequisites for planning MFs (Zhang \& von Dran, 2000). The theory suggests that, if the UI design contains MFs, users will be attracted to visit a new SNS. Therefore, UI designers should include MFs in their design. We empirically tested this idea to advance our understanding about how to effectively design a SNS app.

\subsection{Involvement theory}

Krugman (1965) first introduced the construct of involvement level (IL) in investigating consumer behaviour. An individual's involvement level is based on inherent needs, values and interests that motivate one toward the object (Zaichkowsky, 1994): that is, an individual's 'level of involvement with an object, situation, or action is determined by the degree to which they perceive that concept to be personally relevant' (p.211). IL is regarded as one of the critical factors influencing an individual's behaviours. For example, Shiau and Luo (2013) conducted research on blogs and found that users' IL has a positive impact on the tendency toward continuous use of blogs. Users' IL also affects their satisfaction with searching the Internet for information (Santosa, Wei, \& Chan, 2005). While the use of involvement theory provides insights to website development such as blogs (e.g., Santosa, Wei, \& Chan, 2005), we contend that the interaction effect of MF and IL has been less addressed.

We argue that MF and IL should be considered jointly for their impact of BI. While MFs can lead to an 'internal process' that increases an individual's satisfaction level, IL represents an 'external process' that is an individual's willingness to spend more time on the objects involved. Considering these two processes together, we argue that user behavioural intentions on SNS apps will be influenced by MFs and IL jointly through a well-established model, TAM. The details of TAM are discussed in the section below. In this study, we built on prior research by defining high/low SNS IL as being possessed by people who show a high/low level of care about SNSs. We expected that users with high/low IL are willing to spend more/less time on the SNSs they attach to. Consequently, the amount of time attached to SNSs moderates the relationship between MFs and users' perceptions (i.e., TAM) of the SNS app.

\subsection{Technology acceptance model (TAM)}

In this section, we first explain TAM and how it relates to users' BI. Second, we explain why we expect MFs will have an impact on TAM.

The TAM is an information systems theory that models how users come to accept and use a technology. The model suggests that, when users are presented with a new technology, a number of factors influence their decision about how and when they will use it, including perceived ease of use (PEOU), perceived usefulness (PU) and perceived playfulness (PP). The TAM is frequently used to explain user willingness to adopt certain technologies (Davis, 1989). In this model, both PEOU and PU affect users' BI when one considers a website as a new piece of information technology; PEOU represents ease of use when users interact with an interface; 
PU refers to a website system's functionality; and BI represents the individual willingness to use the website ( $\mathrm{Lin} \& \mathrm{Lu}, 2000$ ). Of these, PU plays an important role in determining whether users accept certain information technologies (Lu, Zhou, \& Wang, 2009; Sledgianowski \& Kulviwat, 2009; Yen, Wu, Cheng, \& Huang, 2010). When it comes to SNSs in particular, PU has a direct impact on BI (Kang \& Lee, 2010; Kwon \& Wen, 2010; Sledgianowski \& Kulviwat, 2009). Another important construct in TAM is PEOU (Davis, 1989). Before accepting and using any type of technological product, users must first overcome the initial barriers of ease of use. Thus, PEOU comprises the fundamental decision factor in users' consideration of whether they should continue to use a particular SNS app (Choi \& Chung, 2013).

In their research study on the acceptance level of the World Wide Web (WWW), Moon and Kim (2001) adopted the PP factor and applied it to TAM. They argue that technological products which are not easy to use will reduce users' PP. At the same time, technological products with high ease of use reduce users' sense of threat during operations. Research has shown that PP has a positive impact on BI (Moon \& Kim, 2001). Thus, playfulness is a key factor affecting user intentions to visit specific websites. In other words, if users 'feel good' when using a system or performing a task, they are encouraged to engage more with that system or activity. Lin, $\mathrm{Wu}$, and Tsai (2005) pointed out that, when users participate in website activities with feelings of pleasure and enjoyment, their preferences for those activities increase, as does their willingness to revisit the website. In addition, SNS app interface designers add many entertainment functions, in line with their goal of stimulating users' perceived interest levels in using the app. This is done with the hope of increasing users' pleasure in using the app and of enhancing users' BI.

In the context of a SNS app, we believe MFs play a part in explaining users' acceptance and usage of the SNS app. Incorporating the MFs into the TAM provides better prediction of user acceptance and usage of a SNS app. According to the two-factor theory, MFs exert crucial influence on users' satisfaction level and perceptions on achievement expectations (Vansteenkiste, Simons, Lens, Sheldon, \& Deci, 2004). Adding MFs into a SNS app will stimulate users to appropriate various testing strategies to use the SNS app in order to reach the increased satisfaction level and achievement expectations based on their current knowledge, skills and experience. During the learning process stimulated by MFs, users are inclined to believe that their satisfaction level is increased by using the particular SNS app. Then, given the time and effort they allocated to the SNS app, their perceived ease-of-use will be increased accordingly. Also, given the increased level of satisfaction driven by MFs, user intention to reuse the SNS app increases, because they feel good when performing tasks in the SNS app. Based on this reasoning, we suggest that IL and MFs jointly influence users' BI through TAM (i.e., PU, PEOU, and PP). Figure 1 shows this theoretical model. 


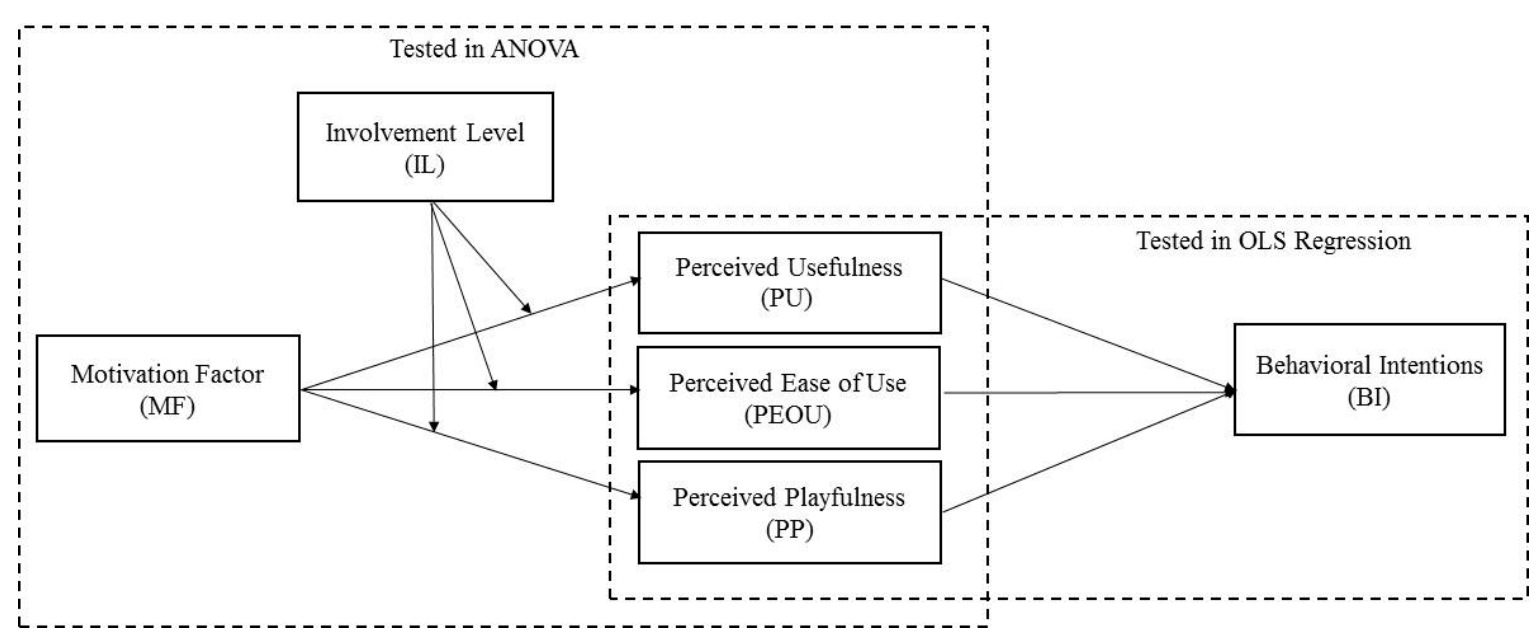

Figure 1. Theoretical model

\section{Research Design and Methodology}

We conducted two experimental studies. Study 1 investigated MFs, and Study 2 examined the impact of these MFs using a pseudo-SNS app (Unicorn). We recruited participants from a large university in Taiwan. Student participants from Taiwan were particularly suitable for this study given the fact that the population were active social media users. A research report shows that, in the fourth quarter $2016,81 \%$ of the population were active social media users, and the most popular social network was FB, with an 83\% penetration rate (Statista, 2017). To be more specific, in Study 1, two-factor theory is applied to unpack potential users' demands in order to identify the HFs and MFs of a SNS app's UI. In Study 2, we then examine the effect of those MFs on BI. The aim of Study 2 is to determine whether the UI-integrated MFs can stimulate a user's BI, as predicted by two-factor theory (Tuch \& Hornbæk, 2015), or if they actually demotivate a user's BI due to the demand for additional HFs or the inherent delay of perception or confidence in using the new UI. We conducted a $2 \times 2$ mixed-factorial experimental design, manipulating for two factors as the repeated tests: the between-subject factor (the IL, both high and low) and the within-subject factor (the SNS app UI, with and without MFs). We manipulate for IL because users' IL with SNSs and their awareness of interface design are not always the same. We adopted Krugman's (1965) involvement theory to identify participants' IL with the SNS. We also measured participants' PU, PEOU, and PP of the SNS app, using TAM as the mediator.

In Study 1, we incorporated three main dimensions from popular interface design evaluation principles. These are: 'visuals,' 'usability' and 'functionality.' We used an online survey to investigate user perception of the HFs and MFs of SNSs. For this survey, we used a list with 41 core features (based on the literature review from Zhang and von Dran 2000, and Wu et al., 2008) and allocated each of these to one of three categories: visuals, usability, and functionality. We asked participants to identify whether specific features were an HF or an MF. To do so, we adopted Zhang and von Dran's (2000) procedure to ask participants to classify each feature to one of four possible options: Hygiene (basic function: if not present, users will complain), Motivation (additional function: if present, will satisfy users), Unclear H/M (unclear whether basic or additional function: a "useless factor"), or Unclear Wording (the description is difficult for a participant to understand: a "useless factor"). We adopted these four options for 
participants to use in identifying whether specific features of the SNS app belong to the category of $\mathrm{HF}$ or MF.

We adopted questionnaire items from Zhang and von Dran (2000) and Wu et al. (2008), and revised these based on the characteristics of our task (SNS apps), which resulted in the items being slightly different from Zhang and von Dran (2000) and Wu et al. (2008). In addition, we referred to the social media report 2012 (Nielsen, 2012) to help us filter the top five SNS apps in 2012. These were determined to be Facebook, Twitter, Foursquare, Google+, and Pinterest. Consequently, the questionnaire consists of 11 items in the visuals category, and 15 items each in the usability and functionality categories. These items are listed in Appendix 1. Then we calculated the percentage of each feature that was selected from the questionnaires. More details about how we decided HFs and MFs is in section 3.3. Based on the result of the questionnaires, we can determine which item is HF and which item is MF. Then, to test our theoretical model, we conducted another study. The first step was to develop a pseudo SNS app. We designed a pseudo SNS app which incorporated both HFs and MFs in its design.

In Study 2, we unpacked the causal relationship between MFs and BIs in relation to SNS app. Employing online surveys as the experiment's method, we manipulated for two factors: IL (high and low) and MFs (with and without). The levels of each factor are described below. The SNS app with MFs is the one that we added MFs to-the virtual app, which we called Unicorn. The MFs introduced here were those retrieved from our Study 1. In this experimental task, we used the Facebook app as the SNS app without any MFs. Thus, a 2x2 experimental design was adopted in Study 2.

The participants were asked to complete five tasks (see Appendix 2) to experience MFs in the use of the Unicorn app. After completing those five tasks, all participants had to complete questionnaires, which included measures for both IL and TAM. We used the personal involvement inventory (PII) from Zaichkowsky (1994) as the measure for participants' IL. To measure participants' PU, PEOU, PP and BI, we used the questionnaire from Moon and Kim (2001), which includes four sections that measure for PU, PEOU, PP and BI. All items were measured using a 5-point Likert scale, with anchors ranging from 'strongly disagree' to 'strongly agree' (see Appendix 3).

As recommended by Jiang and Benbasat (2007), we used a two-step test. In the first step, we employed a two-way mixed design ANOVA to examine whether MFs moderated the users' $\mathrm{IL}$, as well as their PU, PEOU and PP. In the second step, a multiple regression was used to test the structural model proposed on the right-hand side of Figure 1. In that step, we tested whether PU, PEOU and PP have the power to explain the variance of BI.

\subsection{Study 1 - Data collection procedure}

We distributed our online survey to 54 participants who were selected by a convenience sampling method from a large university, for a total of 46 usable survey responses over six days (from 18 to 24 April, 2013). We recruited these participants to complete the survey in order to investigate user perception of the HFs and MFs of SNSs. The sample consisted of an equal ratio of genders: $50 \%$ male and 50\% female. Participants ranged in age from 20-35 years old; 18 participants were aged 20 to 24 years old, 23 participants were aged 25 to 29 years old, and the remainder were 30 to 35 years old. A significant number of respondents (28\%) reported regularly spending between two and four hours a day surfing the Internet via smartphones. 
The primary reason reported for time spent surfing online was addiction to SNS apps such as Facebook, with approximately $87 \%$ of all responses citing this reason.

\subsection{Study 1 - Analysis}

Once we collected empirical data using the survey instrument, we could determine whether one item (see Appendix 1) was a MF or HF. We used a left-tailed Z test and adapted the Alpha value as 0.05 , arriving at a confidence level of under $95 \%$ to separately process factor tests for HFs and MFs. Finally, we compared the results of these two tests and listed the final factor for each feature. For the HF test, we tested whether the HFs' percentage was significantly greater than 0.5, which is equal to the MFs' percentage of less than 0.5. Similarly, for the MF test, we tested whether the MFs' percentage is significantly greater than 0.5 , which equals to the $\mathrm{HFs}^{\prime}$ percentage $p$-value less than 0.5 . Note that the $Z \alpha=Z 0.05=-1.645$ and the decision rule was to reject alternative hypotheses if the $Z$ value was less than -1.645 .

\subsection{Study 1 - Results}

The results of our studies show that of those items tested eight were not classified as either being an HF or an MF after our two-factor tests had been conducted, as illustrated in Table 2. These items are: item 2 (Arrange layout on timelines page), item 3 (Background customization), item 22 (Colourful visual design), item 30 (Edit photos), item 31 (Save photos), item 33 (Save message), item 35 (Sort home by categories) and item 38 (Reminder alarm).

The $Z$ value of these eight items was in the twilight zone of $Z$ testing; therefore, those eight items were not identified as HF or MF. Thus, we used 'N/A' to represent them and we did not include them in Study 2 for the MF SNS app (Unicorn) design.

In terms of MFs, the results showed no MFs to be located in the usability category, and only one MF (Dynamic font) in the visuals category. However, there were four MFs in the functionality category (i.e., items 28, 36, 39 and 40, or Virtual gifts, Video call, My favourite, and Incentive mechanisms, respectively). We found that these five MFs are prone to be considered 'interaction functions'. This implies that users looked for the ability to have multiple interactive functions to use in connecting with their friends and peers.

\subsection{Study 2 - Method}

We describe the details of how we designed and developed Unicorn app in this section. The development of Unicorn has four steps within three stages: implementation, deployment and testing.

Implementation. The Unicorn app prototype (see Figure 2) is designed by using the UI design software tool Rightware Kanzi 2.5.2. We have two implementations of this app: one was using this software's graphical library to design Unicorn's layout and animation. The other was based on our finding from Study 1 to generate a user interface-flow diagram to help us acquire a full picture of this app's structure. The user interface-flow diagram is also called a storyboard. The purpose of using a storyboard is to enable a designer to model the relationship between major user interface elements and fundamental usability. Moreover, a storyboard can put the designer in a position where he/she can validate the overall flow of app UI (User interface flow diagrams, 2017).

Deployment. The following are the main development tools that we used: 
- $\quad$ Rightware Kanzi 2.5.2. was utilized to implement a UI framework of information and run the MFs that were implemented in the application

- $\quad$ Application layout, for example, the visual design;

- Application animation, for example, the click response of UI, MFs implementation.

- User interface-flow diagram was used to design each tasks' operating processes for participators to perform this application.

Testing. We chose a 4.3-inch screen (i.e., HTC Sensation smartphone) as the test platform. The range of screen sizes among smartphones was between 3.5 and 5.5 inches in width during our experimental period. We selected 4.3 inches because this is the average screen size. A final prototype was rolled out to all 71 participating users from a large university in Taiwan. They were asked to complete five tasks to experience. These tasks include 'dynamic font', 'video call', 'my favourite', 'incentive mechanisms', and 'virtual gifts'. For example, in the video-call task, participants were asked to look for specific contacts from the friend list, and select the video call button to make the call. After finishing the call, they pressed the end button to hang up the call, and go back to home page. Appendix 2 provides more details about these tasks. 


\begin{tabular}{|c|c|c|c|c|c|c|c|c|c|c|c|c|}
\hline \multirow{2}{*}{ Cat } & \multirow{2}{*}{ Items } & \multicolumn{5}{|c|}{ Hygiene factor test result } & \multicolumn{5}{|c|}{ Motivation factor test result } & \multirow{2}{*}{$\begin{array}{c}\text { Final } \\
\text { Factor }\end{array}$} \\
\hline & & Freq & $\%$ & $\mathrm{Z}$ & H1 & Factor & Freq & $\%$ & $\mathrm{Z}$ & H1 & Factor & \\
\hline \multirow{15}{*}{ 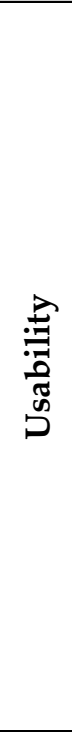 } & 1. See information immediately & 34 & 94.44 & 5.33 & $\mathrm{~A}$ & Hygiene & 2 & 5.56 & -5.33 & $\mathrm{R}$ & Hygiene & Hygiene \\
\hline & 2. Arrange layout on timelines page & 26 & 60.47 & 1.37 & $\mathrm{~A}$ & Hygiene & 17 & 39.53 & -1.37 & $\mathrm{~A}$ & Motivation & $\mathrm{N} / \mathrm{A}$ \\
\hline & 3. Background customization & 19 & 61.29 & 1.26 & A & Hygiene & 12 & 38.71 & -1.26 & A & Motivation & $\mathrm{N} / \mathrm{A}$ \\
\hline & 4. User guide support & 30 & 78.95 & 3.57 & $\mathrm{~A}$ & Hygiene & 8 & 21.05 & -3.57 & $\mathrm{R}$ & Hygiene & Hygiene \\
\hline & 5. Swipe pages & 44 & 97.78 & 6.41 & A & Hygiene & 1 & 2.22 & -6.41 & $\mathrm{R}$ & Hygiene & Hygiene \\
\hline & 6. The latest articles on the top & 41 & 93.18 & 5.73 & $\mathrm{~A}$ & Hygiene & 3 & 6.82 & -5.73 & $\mathrm{R}$ & Hygiene & Hygiene \\
\hline & 7. Go back & 39 & 97.50 & 6.01 & $\mathrm{~A}$ & Hygiene & 1 & 2.50 & -6.01 & $\mathrm{R}$ & Hygiene & Hygiene \\
\hline & 8. Go back home & 43 & 95.56 & 6.11 & A & Hygiene & 2 & 4.44 & -6.11 & $\mathrm{R}$ & Hygiene & Hygiene \\
\hline & 9. Loading status icon & 32 & 88.89 & 4.67 & A & Hygiene & 4 & 11.11 & -4.67 & $\mathrm{R}$ & Hygiene & Hygiene \\
\hline & 10. Stability while in operation & 34 & 91.89 & 5.10 & A & Hygiene & 3 & 8.11 & -5.10 & $\mathrm{R}$ & Hygiene & Hygiene \\
\hline & 11. Multiple languages selection & 28 & 68.29 & 2.34 & A & Hygiene & 13 & 31.71 & -2.34 & $\mathrm{R}$ & Hygiene & Hygiene \\
\hline & 12. Save information & 35 & 83.33 & 4.32 & A & Hygiene & 7 & 16.67 & -4.32 & $\mathrm{R}$ & Hygiene & Hygiene \\
\hline & 13. Click link accurately & 38 & 86.36 & 4.82 & $\mathrm{~A}$ & Hygiene & 6 & 13.64 & -4.82 & $\mathrm{R}$ & Hygiene & Hygiene \\
\hline & 14. Privacy setting & 43 & 93.48 & 5.90 & A & Hygiene & 3 & 6.52 & -5.90 & $\mathrm{R}$ & Hygiene & Hygiene \\
\hline & 15. Authority for restricting reading articles & 39 & 86.67 & 4.92 & $\mathrm{~A}$ & Hygiene & 6 & 13.33 & -4.92 & $\mathrm{R}$ & Hygiene & Hygiene \\
\hline \multirow{11}{*}{ 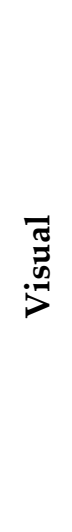 } & 16. Consistency of layout & 36 & 81.82 & 4.22 & A & Hygiene & 8 & 18.18 & -4.22 & $\mathrm{R}$ & Hygiene & Hygiene \\
\hline & 17. Consistency of icons & 35 & 77.78 & 3.73 & A & Hygiene & 10 & 22.22 & -3.73 & $\mathrm{R}$ & Hygiene & Hygiene \\
\hline & 18. Dynamic font & 1 & 6.25 & -3.50 & $\mathrm{R}$ & Motivation & 15 & 93.75 & 3.50 & $\mathrm{~A}$ & Motivation & Motivation \\
\hline & 19. Consistency of font & 37 & 92.50 & 5.38 & $\mathrm{~A}$ & Hygiene & 3 & 7.50 & -5.38 & $\mathrm{R}$ & Hygiene & Hygiene \\
\hline & 20. Consistency of space & 39 & 88.64 & 5.13 & $\mathrm{~A}$ & Hygiene & 5 & 11.36 & -5.13 & $\mathrm{R}$ & Hygiene & Hygiene \\
\hline & 21. Consistency visual & 39 & 88.64 & 5.13 & A & Hygiene & 5 & 11.36 & -5.13 & $\mathrm{R}$ & Hygiene & Hygiene \\
\hline & 22. Colourful visual design & 8 & 42.11 & -0.69 & A & Hygiene & 11 & 57.89 & 0.69 & A & Motivation & $\mathrm{N} / \mathrm{A}$ \\
\hline & 23. Main functions on top of home & 36 & 97.30 & 5.75 & A & Hygiene & 1 & 2.70 & -5.75 & $\mathrm{R}$ & Hygiene & Hygiene \\
\hline & 24. Main functions on bottom of home & 23 & 76.67 & 2.92 & A & Hygiene & 7 & 23.33 & -2.92 & $\mathrm{R}$ & Hygiene & Hygiene \\
\hline & 25. Swipe while reading albums & 30 & 75.00 & 3.16 & A & Hygiene & 10 & 25.00 & -3.16 & $\mathrm{R}$ & Hygiene & Hygiene \\
\hline & 26. Clear icons to identify & 44 & 95.65 & 6.19 & A & Hygiene & 2 & 4.35 & -6.19 & $\mathrm{R}$ & Hygiene & Hygiene \\
\hline
\end{tabular}




\begin{tabular}{|c|c|c|c|c|c|c|c|c|c|c|c|c|}
\hline \multirow{2}{*}{ Cat } & \multirow{2}{*}{ Items } & \multicolumn{5}{|c|}{ Hygiene factor test result } & \multicolumn{5}{|c|}{ Motivation factor test result } & \multirow{2}{*}{$\begin{array}{c}\text { Final } \\
\text { Factor }\end{array}$} \\
\hline & & Freq & $\%$ & $\mathbf{Z}$ & H1 & Factor & Freq & $\%$ & $\mathbf{Z}$ & H1 & Factor & \\
\hline \multirow{15}{*}{ 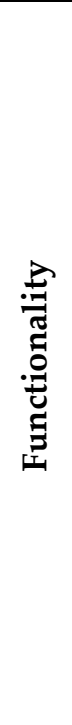 } & 27. Share location & 33 & 78.57 & 3.70 & $\mathrm{~A}$ & Hygiene & 9 & 21.43 & -3.70 & $\mathrm{R}$ & Hygiene & Hygiene \\
\hline & 28. Virtual gifts & 3 & 18.75 & -2.50 & $\mathrm{R}$ & Motivation & 13 & 81.25 & 2.50 & A & Motivation & Motivation \\
\hline & 29. Photography & 29 & 76.32 & 3.24 & $\mathrm{~A}$ & Hygiene & 9 & 23.68 & -3.24 & $\mathrm{R}$ & Hygiene & Hygiene \\
\hline & 30. Edit photos & 14 & 37.84 & -1.48 & $\mathrm{~A}$ & Hygiene & 23 & 62.16 & 1.48 & $\mathrm{~A}$ & Motivation & $\mathrm{N} / \mathrm{A}$ \\
\hline & 31. Save photos & 28 & 62.22 & 1.64 & A & Hygiene & 17 & 37.78 & -1.63 & A & Motivation & $\mathrm{N} / \mathrm{A}$ \\
\hline & 32. Tag friends & 33 & 78.57 & 3.70 & $\mathrm{~A}$ & Hygiene & 9 & 21.43 & -3.70 & $\mathrm{R}$ & Hygiene & Hygiene \\
\hline & 33. Save message & 13 & 40.63 & -1.06 & $\mathrm{~A}$ & Hygiene & 19 & 59.38 & 1.06 & $\mathrm{~A}$ & Motivation & $\mathrm{N} / \mathrm{A}$ \\
\hline & 34. Like function & 40 & 95.24 & 5.86 & A & Hygiene & 2 & 4.76 & -5.86 & $\mathrm{R}$ & Hygiene & Hygiene \\
\hline & 35. Sort home by categories & 19 & 59.38 & 1.06 & $\mathrm{~A}$ & Hygiene & 13 & 40.63 & -1.06 & $\mathrm{~A}$ & Motivation & $\mathrm{N} / \mathrm{A}$ \\
\hline & 36. Video call & 9 & 28.13 & -2.47 & $\mathrm{R}$ & Motivation & 23 & 71.88 & 2.47 & $\mathrm{~A}$ & Motivation & Motivation \\
\hline & 37. Emotional icon for texting & 28 & 70.00 & 2.53 & $\mathrm{~A}$ & Hygiene & 12 & 30.00 & -2.53 & $\mathrm{R}$ & Hygiene & Hygiene \\
\hline & 38. Reminder alarm & 24 & 61.54 & 1.44 & $\mathrm{~A}$ & Hygiene & 15 & 38.46 & -1.44 & $\mathrm{~A}$ & Motivation & $\mathrm{N} / \mathrm{A}$ \\
\hline & 39. My favourite & 3 & 15.00 & -3.13 & $\mathrm{R}$ & Motivation & 17 & 85.00 & 3.13 & $\mathrm{~A}$ & Motivation & Motivation \\
\hline & 40. Incentive mechanisms & 1 & 6.25 & -3.50 & $\mathrm{R}$ & Motivation & 15 & 93.75 & 3.50 & A & Motivation & Motivation \\
\hline & 41. Search function & 38 & 90.48 & 5.25 & $\mathrm{~A}$ & Hygiene & 4 & 9.52 & -5.25 & $\mathrm{R}$ & Hygiene & Hygiene \\
\hline
\end{tabular}

Table 2. Two-factor test result 


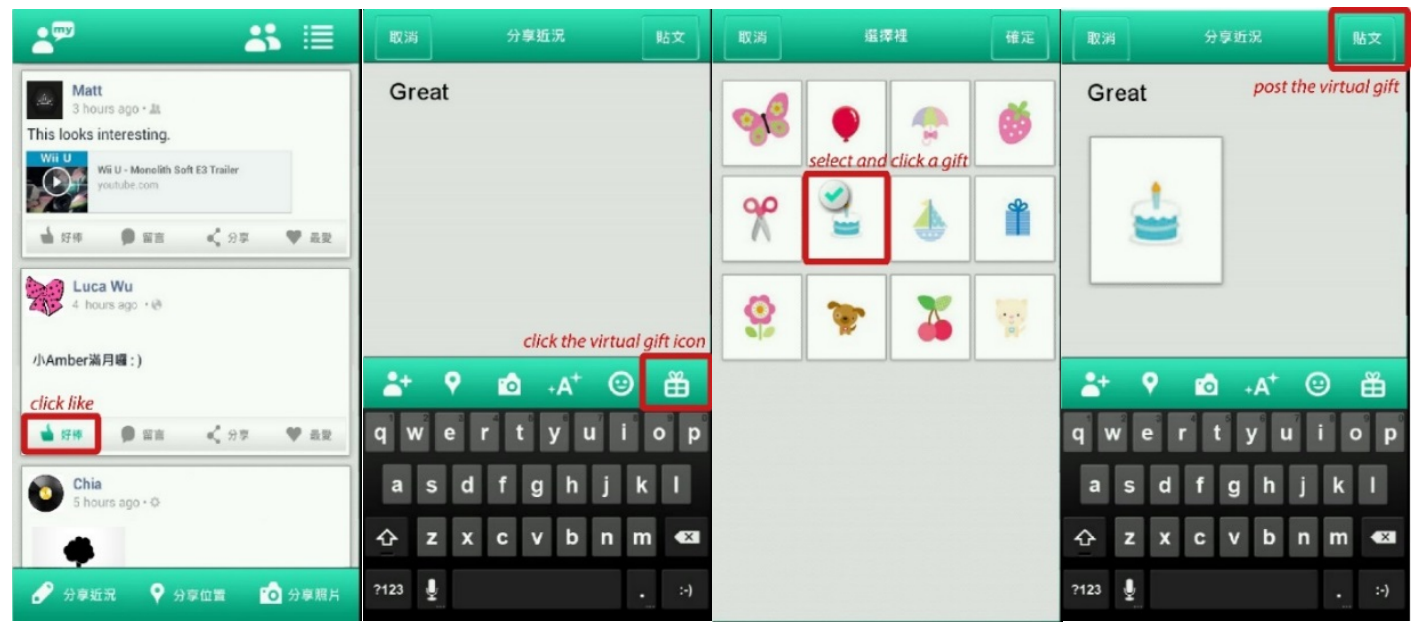

Virtual gifts
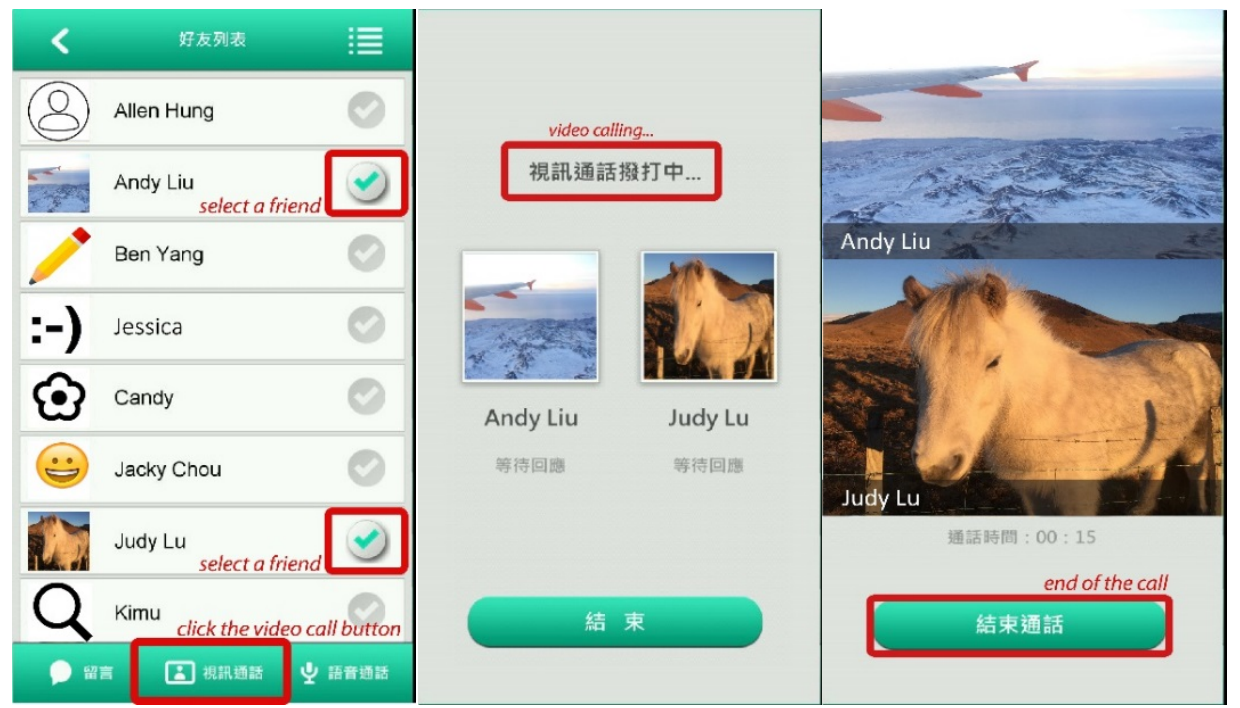

Video call

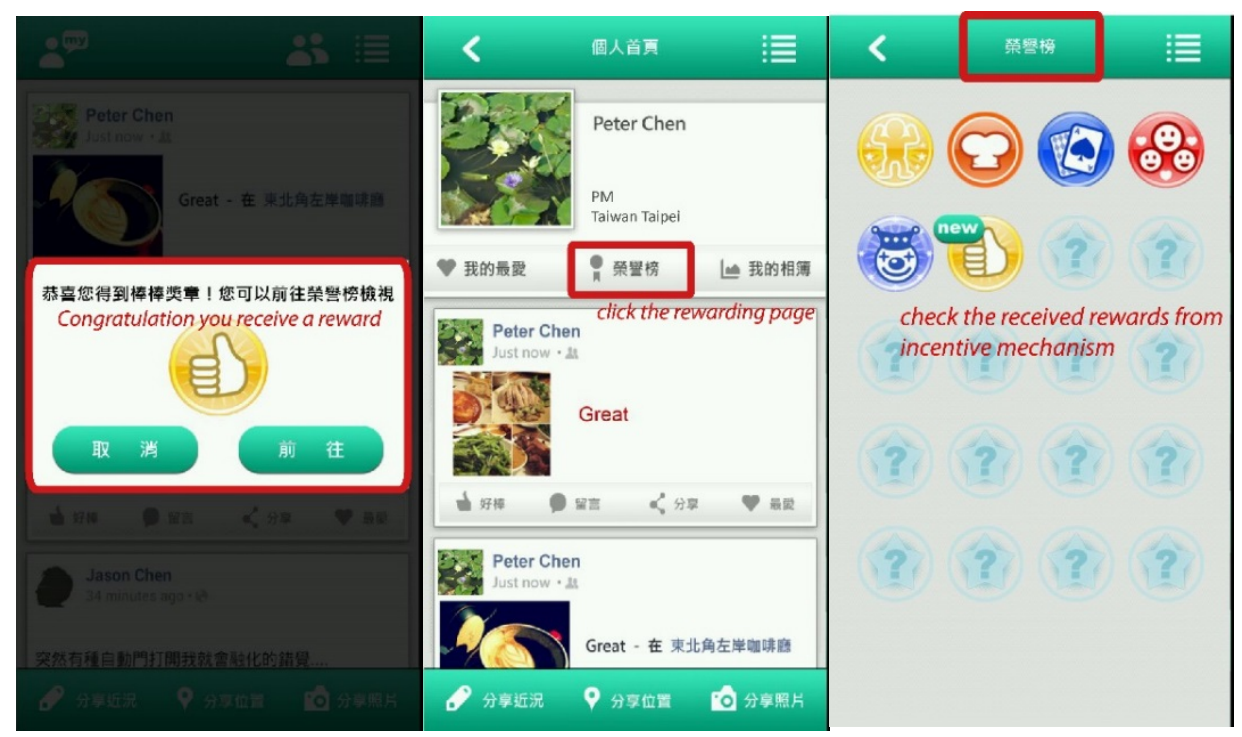

Incentive mechanisms

Figure 2. The UI of Unicorn 


\subsection{Study 2 - Data collection procedure}

In Study 2, 71 students were selected through a convenience sampling method from a large university in Taiwan. Each participant had to complete the experimental task (i.e., operationalise the Facebook app and the Unicorn app) and fill out the online survey. Meanwhile, we observed participants' behaviour on using the Unicorn app by an unobtrusive naturalistic observation method when participants executed the experimental task. In order to get deep insights about participants' perspectives and feelings about this app, we employed a short semi-structured interview after they completed the experimental task. The purpose is to gather more descriptive data on their personal experiences of the experimental task. Due to this purpose, we asked the participants the following questions: how do you feel after executing the experimental task? Which motivation feature does you prefer the most? What is your willingness to continue using this app (Unicorn)? Finally, do you have any comments/ suggestions that you would like to provide to us?

We concluded with 66 valid survey responses over six days (from 16 to 21 June, 2013). There were 35 male and 31 female participants, with average ages of 20-24 years old (18.27\%), 25-29 years old (23.35\%) and $30-34$ years old (25.38\%). Note that there is no overlapping in samples between Study 1 and Study 2. In addition, 66\% reported that they spent between two and four hours a day surfing the Facebook app via smartphone devices.

We used the Facebook app as a base because the MFs, which we developed in Study 1, had not yet been implemented in the Facebook app while we were conducting this study. In addition, all participants had experience in using the Facebook app. Therefore, the participants were able to compare the differences between the Facebook app and Unicorn app.

\subsection{Study 2 - Analysis}

Table 3 presents the correlations and descriptive statistics for all Study 2 variables. In our reliability analysis (shown in Appendix 4), since the Cronbach's alpha values of all the constructs - with one minor exception in the SPSS results - were over 0.8, we determined that all of the variables are reliable.

\begin{tabular}{|l|l|l|l|l|l|l|}
\hline & Variable & $\mathbf{1 . P U}$ & 2. PEOU & 3.PP & 4.BI & 5.IL \\
\hline \multirow{4}{*}{$\begin{array}{l}\text { Descriptive } \\
\text { statistics }\end{array}$} & Mean & 3.66 & 3.94 & 3.39 & 3.78 & 3.57 \\
\cline { 2 - 7 } & Median & 3.67 & 3.89 & 3.33 & 3.33 & 2.10 \\
\cline { 2 - 7 } & SD & 0.46 & 0.56 & 0.53 & 0.71 & 0.46 \\
\cline { 2 - 7 } & Range & $2.11-5.00$ & $2.22-5.00$ & $1.89-5.00$ & $1.00-5.00$ & $2.30-4.40$ \\
\cline { 2 - 7 } & $\mathrm{n}$ & 132 & 132 & 132 & 132 & 66 \\
\hline \multirow{5}{*}{ Correlations } & $1 . \mathrm{PU}$ & & & & & \\
\cline { 2 - 7 } & $2 . \mathrm{PEOU}$ & $0.24^{* *}$ & & & & \\
\cline { 2 - 7 } & 3.PP & $0.62^{* *}$ & $0.20^{*}$ & & & \\
\cline { 2 - 7 } & $4 . \mathrm{BI}$ & $0.57^{* *}$ & $0.25^{* *}$ & $0.64^{* *}$ & & \\
\cline { 2 - 7 } & $5 . \mathrm{IL}$ & $0.38^{* *}$ & 0.13 & $0.48^{* *}$ & $0.40^{* *}$ & \\
\hline
\end{tabular}

Note: ${ }^{*} P<0.05 ;{ }^{* *} P<0.01$

Table 3. Table of descriptive statistic and correlations for pilot study variables

The average IL for SNSs was found to be 3.57 out of 5 . We adopted a common practice in social science - median split - to turn the continuous variable (e.g., IL) into a categorical one. Essentially, the idea was to categorise one participant as high IL if his/her IL value was above the median, which shows an increasing trend, or categorise one as low IL if his/her IL value was below the median, which shows a decreasing trend. As shown in Figure 3, our results 
showed that 36 respondents fell into the category of high involvement subjects, while 30 were low IL participants.

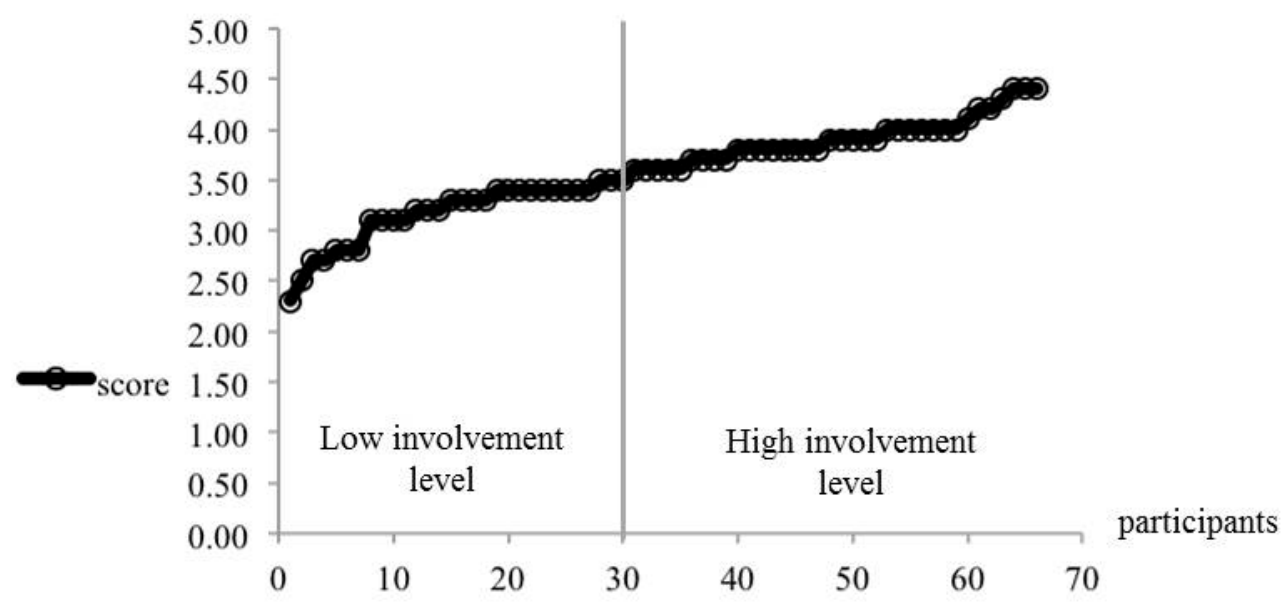

Figure 3. Involvement level distribution

Based on the theoretical model shown in Figure 1, we theorized IL as the moderator between MFs and PU, PEOU and PP. Therefore, we employed ANOVA on PU, PP and PEOU (each alone) to examine whether IL, MF and the interaction between IL and MF yielded a significant effect on those three dependent variables. These test results are provided below.

\subsection{ANOVA results on PU}

We found that the Facebook app facilitated high IL participants to have a higher physical experience in relation to PU than in regard to the other TAM construct variables. As the descriptive statistics summary in Table 4 shows, the mean of high IL participants for this variable is significantly higher than the mean of low IL participants, especially for the Unicorn app. The significant value of this interaction effect between IL and MFs suggests that the effects of IL are moderated by MFs (see Table 5). Specifically, IL and MFs had significant effects on PU ( $p<0.01$ and $p<0.05$, respectively). Figure 4 shows the interaction effect of MFs and IL on BI. According to the Figure, the participants with high IL perceived higher PU than those with low IL in both types of SNS apps (with and without MFs).

Interestingly, participants with high IL perceived lower PU when using the Unicorn app than when using Facebook app, while participants with low IL did not perceive the difference in PU between the Unicorn and Facebook apps. Thus, there is a significant interaction effect between MFs and IL on BI $(p<0.05)$.

\begin{tabular}{|l|l|l|c|c|}
\hline Motivation factor (MF) & Involvement level (IL) & mean & SD & n \\
\hline \multirow{3}{*}{ Yes } & Low & 3.46 & 0.30 & 30 \\
\cline { 2 - 5 } & High & 3.67 & 0.47 & 36 \\
\cline { 2 - 5 } & Total & 3.57 & 0.41 & 66 \\
\hline \multirow{3}{*}{ No } & Low & 3.49 & 0.45 & 30 \\
\cline { 2 - 5 } & High & 3.98 & 0.43 & 36 \\
\cline { 2 - 5 } & Total & 3.75 & 0.50 & 66 \\
\hline
\end{tabular}

Table 4. Descriptive statistics table for $\mathrm{PU}$

\begin{tabular}{|l|c|c|c|c|c|} 
Source & SS & df & MS & F & p-value \\
\hline
\end{tabular}




\begin{tabular}{|l|l|l|l|l|l|}
\hline Involvement level (IL) & 4.02 & 1 & 4.02 & 19.58 & $0.00^{*}$ \\
\hline Motivation factor (MF) & 0.94 & 1 & 0.94 & 0.00 & $0.01^{*}$ \\
\hline IL X MF & 0.60 & 1 & 0.60 & 4.08 & $0.05^{*}$ \\
\hline Within-subjects & 22.60 & 128 & & & \\
\hline Block (IF) & 13.13 & 64 & 0.21 & & \\
\hline Error (MF) & 9.47 & 64 & 0.15 & & \\
\hline Total & 28.16 & 131 & & & \\
\hline
\end{tabular}

Note: ${ }^{*} P<0.05$

Table 5. ANOVA summary table for PU

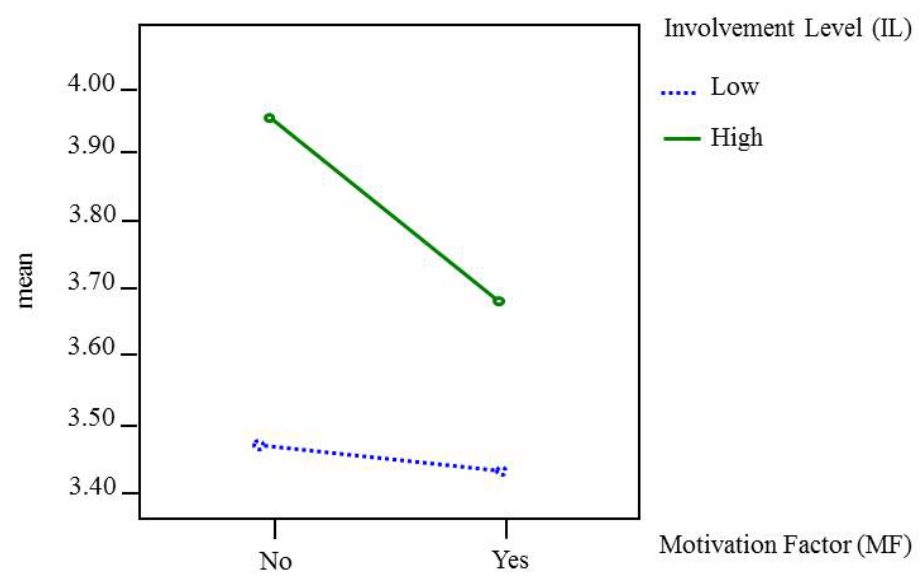

Figure 4. Interaction graph of MF and IL on PU

\subsection{ANOVA results on PEOU}

We did not find a significant interaction effect of MFs and ILs on PEOU ( $p=0.82)$.

\subsection{ANOVA results on PP}

We found that there is a significant difference in PP between high IL and low IL ( $p<0.01$ ), while MF and IL x MF had no significant effect on PP (see Table 6). This result indicates that participants' different levels of IL have an impact on their sense of PP in relation to both SNS apps (with and without MFs). In addition, Table 7 shows that high IL participants have a higher sense of PP than those with low IL on both SNS apps.

\begin{tabular}{|l|l|l|l|l|l|}
\hline \multicolumn{1}{|c|}{ Source } & \multicolumn{1}{c|}{ SS } & \multicolumn{1}{c|}{ df } & \multicolumn{1}{c|}{ MS } & \multicolumn{1}{c|}{ F } & p-value \\
\hline Involvement level (IL) & 8.46 & 1 & 8.46 & 29.64 & $0.00^{*}$ \\
\hline Motivation factor (MF) & 0.02 & 1 & 0.02 & 0.14 & 0.71 \\
\hline IL X MF & 0.15 & 1 & 0.15 & 0.96 & 0.33 \\
\hline Within-subjects & 28.25 & 128 & & & \\
\hline Block (IF) & 18.26 & 64 & 0.29 & & \\
\hline Error (MF) & 9.99 & 64 & 0.16 & & \\
\hline Total & 36.87 & 131 & & & \\
\hline
\end{tabular}

Note: ${ }^{*} P<0.05$

Table 6. ANOVA summary table for PP

\begin{tabular}{|l|l|c|c|c|}
\hline Motivation factor (MF) & Involvement level (IL) & mean & SD & n \\
\hline \multirow{2}{*}{ Yes } & Low & 3.13 & 0.41 & 30 \\
\cline { 2 - 5 } & High & 3.57 & 0.49 & 36 \\
\hline
\end{tabular}




\begin{tabular}{|l|l|l|l|l|}
\hline & Total & 3.37 & 0.50 & 66 \\
\hline \multirow{3}{*}{ No } & Low & 3.09 & 0.50 & 30 \\
\cline { 2 - 5 } & High & 3.66 & 0.47 & 36 \\
\cline { 2 - 5 } & Total & 3.40 & 0.56 & 66 \\
\hline
\end{tabular}

Table 7. Descriptive statistics table for PP

During the second step, we employed a multiple regression test to help identify which variables made significant contributions to predicting users' BI. The test results (see Table 8) show that the TAM had a significant effect on the dependent variable of $B I(p<0.00)$, for which the explained variance was $45 \%$; $\mathrm{R}^{2}=0.45$, F-value $=36.35, \mathrm{p}<0.01$ ). These results indicate that the participants' PU and PP had a significant effect on BI. By following this with the application of a multiple regression test on each independent variable, we found that PU and PP had a significant effect on $B I$, as $\beta$ (coefficient) $=0.24(t=2.83, p<0.01)$ for $P U$ and $\beta=0.47(t=5.67$, $p$ $<0.01$ ) for PP (see Table 9). Interestingly, PEOU is not shown to have a direct influence on BI as $\beta=0.10(t=1.51, p>0.05)$. Notably, the effect of PP on participants' BI to use SNS app was very strong, as shown by the path coefficient of 0.47 , which was higher than the PU of 0.24 (also see Figure 5). The results from this regression analysis imply that PP played an important role in influencing participants' BI to use SNS app, and that PU was the second most significant key factor. Furthermore, it indicates that users' PP and PU experiences determined whether they decided to keep using SNS app or not.

We also evaluated whether there was a multi-collinearity issue within our model (shown in Table 9). We found that all variance inflation factors (VIF) were less than 5 and the conditional index (CI) was less than 30 . Thus, the degree of multi-collinearity was slight in this model and could be ignored.

\begin{tabular}{|c|c|c|c|c|}
\hline Dependence variable & Adjusted R & df & F-value & p-value \\
\hline Behavioural intentions (BI) & 0.45 & 3 & 36.35 & $0.00^{* *}$ \\
\hline
\end{tabular}

Note: ${ }^{* *} P<0.01$

Table 8. The summary descriptive statistics table on the TAM of behavioural intentions

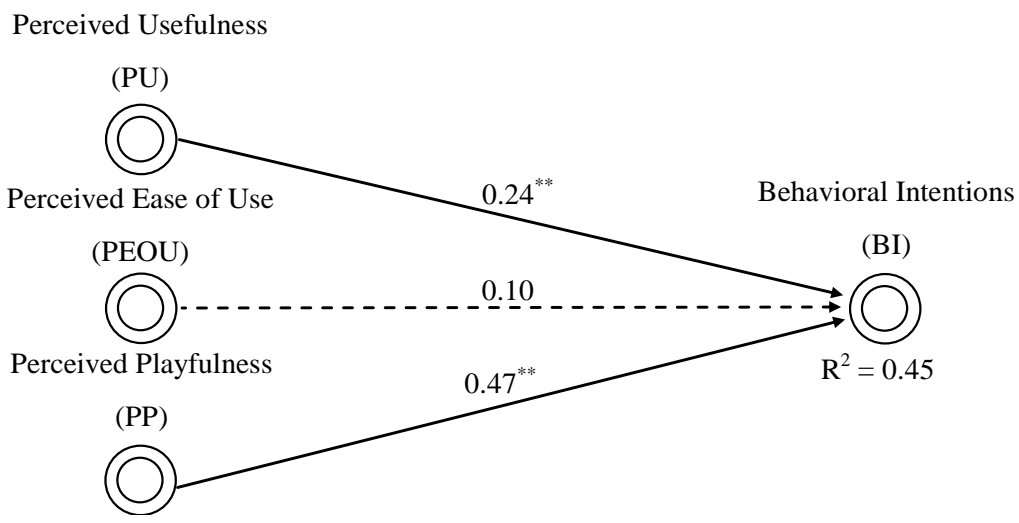

Figure 5. Path coefficient summary

\begin{tabular}{|l|l|l|l|l|l|l|l|}
\hline \multicolumn{1}{|c|}{ Variable } & \multicolumn{1}{c|}{ B } & \multicolumn{1}{c|}{ SE } & \multicolumn{1}{c|}{ Beta } & \multicolumn{1}{c|}{ t } & p-value & \multicolumn{1}{c|}{ VIF } & \multicolumn{1}{c|}{ CI } \\
\hline Perceived usefulness (PU) & 0.36 & 0.13 & 0.24 & 2.83 & $0.01^{* *}$ & 1.67 & 14.48 \\
\hline Perceived ease of use (PEOU) & 0.13 & 0.09 & 0.10 & 1.51 & 0.14 & 1.07 & 21.04 \\
\hline Perceived playfulness (PP) & 0.63 & 0.11 & 0.47 & 5.67 & $0.00^{* *}$ & 1.64 & 25.09 \\
\hline
\end{tabular}

Note: ${ }^{* *} P<0.01$ 


\section{Table 9. The summary table of regression coefficients}

In conclusion, based on this two-step test, we found that MFs negatively influenced users' BI. This meant that users' BI for revisiting the Unicorn app decreased, especially for addicted SNS users. However, the Facebook app attracted users' physical experience of PU and PP by enhancing their BI to revisit the app.

\section{Discussion}

In this study, we address an interesting empirical question: Why is it that some innovative UI designs effectively (and counter-intuitively) demotivate users' behavioural intentions? Based on our findings, we advance the understanding of UI design in SNS app accordingly. To the authors' knowledge, this is the first empirical study to explore the effect of the MFs on users' $\mathrm{BI}$ in the context of SNS apps. We aim to investigate why innovative designs may demotivate user intention to adopt or accept a new SNS app due to its UI design or functions. Although the theory suggests that MFs can enhance user satisfaction level on a particular object, our study suggests that, in a context of SNS apps, MFs may have a negative impact on PU, and consequently, on users' BI. Moreover, consistent with prior research, our results show that IL has a positive impact on PP, and consequently on BI; and users' IL strengthens the negative relationship between MFs and BI through PU. This set of results advances our understanding of users' behaviours on the acceptance or adoption of a new SNS app from an organisational psychology perspective (Chiang, 2013). We discuss theoretical implications below, and followed by managerial implications, limitations and future research directions.

\subsection{Theoretical implications}

The first theoretical contribution is that we investigate how to design SNS apps based on organisational psychology theory. To be more specific, we applied Herzberg's two-factor theory and IL theory to advance our understanding about the impact of design factors on the TAM and, consequently, on BIs. This line of inquiry is significantly different from prior studies in this stream of research. Thus our study provides unique insights and a different perspective on the design of SNS apps, based on the theories we have applied (e.g., Aladwani, 2015). In addition, our finding constitutes a novel and intriguing contribution to two-factor theory. While scholars and practitioners from motivational theory suggest that MFs could stimulate users' visiting intention due to an increase of satisfaction level, we argue that MFs could decrease a user's behaviour intention in accepting or adopting a new or renovated SNS app. For example, in data drawn from interviews and a survey, Aladwani (2015) argued that both HFs and MFs facilitate the use of Twitter. However, unlike prior researchers, who have approached the facilitators of the use of SNS apps from an inductive perspective, we favour the deductive approach (e.g., experiments), because it provides a better opportunity for building a generalizable theory of the UI design of SNS apps that is not simply a reflection of characteristics idiosyncratic to just a single SNS context (e.g., Twitter). We believe that taking the deductive approach allows for the development of finer-grained models than those which can be derived from inductive approaches (Wiseman, Cuevas-Rodríguez, \& Gomez-Mejia, 2012). Our study makes a unique contribution to two-factor theory by extending its application to the adoption or acceptance of a new SNS app as a unique context, while prior applications of the theory focus on job satisfaction in workplaces (Herzberg, 1959; Herzberg, 1987). 
The second contribution is our finding that different design elements have unequal not equal importance. We found that usability, visuals and functionality, which are assumed to have equal importance in the literature, actually have varying levels of importance in SNS app. According to Study 1, we argue that elements in usability are HFs, whereas most of the elements in visuals and functionality are HFs, but five are comprised of MFs: 'Dynamic font', 'Virtual gifts', 'Video call', 'My favourite', and 'Incentive mechanisms'.

To further explore the findings in Study 2, we also observed how participants completed Tasks 1 to 5 and then conducted a short interview to explore how they felt about their experience of the Unicorn app. Based on the reciprocal evidence received, we suggest two reasons to explain our findings. First, there might be a significant time delay between understanding the interface and using the interface with confidence, especially for heavy users of SNS apps. One participant from Study 2 reported that it was difficult to keep his attention on the new design, because he wanted to be able to perform multiple tasks at the same time. In other words, he was expecting to be able to complete some tasks faster, but he was hindered by the delay involved in using the new design. As a result, his PU significantly decreased. Thus, designers should consider this delay and how to make it shorter when planning future designs. Second, in two-factor theory, some scholars argue that, before a MF starts to perform as expected, the mechanism first needs to satisfy the need for HFs such as base payment. Therefore, there is a chance that the baseline app did not completely satisfy user demands regarding HFs. Hence, the advanced app, which incorporates MFs, did not succeed. For this reason, UI designers should pay extra attention to meeting users' basic demands before adding any MFs.

\subsection{Managerial implications}

This study also has important practical implications. First, our results provide clear guidance to UI designers regarding whether they should continue investing time and effort to add MFs into the design of SNS apps. While the theory suggests that MFs can enhance people's satisfaction level on particular objects, our results show that in a context of SNS apps MFs may have a negative impact users' BI. Thus, UI designers should be careful when developing the UI for a SNS app with a MF. Second, UI designers should also consider users' IL when developing the UI for a SNS app. While users with high IL exhibit high BI in accepting or adopting a new SNS app, users' IL further enhances the negative relationship between MFs and BI. These findings provide important guidelines to UI designers. Specifically, UI designers can improve users' BI in a new SNS app by appropriately adding MFs when users show a low IL.

\subsection{Limitations and future research directions}

Four limitations of the studies reported here are worth noting, as they point to directions for future research. First, although we designed a new, pseudo-app in Study 2, we acknowledge the possibility that some participants may have felt familiar or unfamiliar with the newly developed app. Future research should consider perceived familiarity as a potential moderator as an extension of the study. Second, regarding the PU, PEOU and PP, participants may have different impacts on their BI depending on the genres of the app. In other words, participants or users may have different priorities for each type of app, when they make the decision to adopt and continue using an app. For example, game or entertainment, news or information, education, commerce, and health care applications may have different utility and appealing aspects. Future research is needed to examine the impact of priority and value on users' adoption decisions. 
Third, in this study we use students as the study sample. A student sample was used because it is relatively homogenous, which is important to experiment research (Calder, Phillips, \& Tybout, 1981). Students subscribe to and use Internet services often. Therefore this population may better fit the purpose of the study (Pizzutti dos Santos \& Basso, 2012). However, a student sample somewhat restricts the generalizability of the results for a broader population. Our study also used non-random and relatively small samples from a large Taiwanese university. There is a concern regarding the sampling biases in this study. Future research can enlarge the sample size with a random sample, and expand the sample demographics to users of varying ages, working experience and backgrounds to further validate and replicate the findings from this study.

Fourth, in this study we mainly investigate how MFs and IL affect users' BI through TAM. Further research should consider other factors possibly influencing users' BI. Future research may investigate different forms of enabling factors to improve users' PU, PEOU and PP. One possibility is to consider the enabling factors suggested in the recent literature, such as web atmospherics and entertainment gratification (Lim, 2015). Fifth, in this study we only examined the MFs jointly, but did not consider the potential effect of each individual MF can have on users' behaviours (Nguyen et al., 2003). Future research can extend this study by investigating both the individual effect and joint effect of MFs on users' perceptions and behaviour on SNS apps. For example, we may expect that there is a difference on the effect of users' BI between an SNS app's functionality and its outlook design.

\section{Conclusion}

Using data collected from two experimental studies, this study examines how MFs and IL independently and jointly influence users' BI on accepting or adopting a new or renovated SNS app through the perception of ease of use, playfulness and usefulness (i.e., TAM). Our study shows that MFs have negative impact on users' BI through PU, but users' IL has a positive impact on users' BI through PP. Further, users' IL enhances the negative relationship between MFs and BI through PU. Future studies are needed to extend this research by examining other cognitive factors, across other study samples, and different genres of SNS apps.

\section{References}

Aladwani, A. M. (2015). Facilitators, characteristics, and impacts of Twitter use: Theoretical analysis and empirical illustration. International Journal of Information Management, 35(1), 15-25.

Carlson, N. (2013). Facebook's new mobile product is a huge flop because it was built by iPhone users. Business Insider. Retrieved 12 December 2017, from http://www.businessinsider.com/facebook-made-a-simple-huge-mistake-buildinghome-which-looks-like-a-bigger-flop-by-the-second-2013-5?IR=T

Calder, B. J., Phillips, L. W., \& Tybout, A. M. (1981). Designing research for application. Journal of Consumer Research, 8(2), 197-207.

Chai, S., \& Kim, M. (2012). A socio-technical approach to knowledge contribution behavior: An empirical investigation of social networking sites users. International Journal of Information Management, 32(2), 118-126. 
Cheng, R. (2013). Here's why the Facebook phone flopped: CNET. Retrieved May 5, 2013, from http://www.cnet.com/news/heres-why-the-facebook-phone-flopped/

Chiang, H. (2013). Continuous usage of social networking sites: The effect of innovation and gratification attributes. Online Information Review, 37(6), 851-871.

Chiang, H., \& Hsiao, K. (2015). YouTube stickiness: the needs, personal, and environment perspective. Internet Research, 25(1), 85-106.

Choi, G., \& Chung, H. (2013). Applying the technology acceptance model to social networking sites (SNS): Impact of subjective norm and social capital on the acceptance of SNS. International Journal of Human-Computer Interaction, 29(10), 619-628.

Chou, W. H., Lai, Y. T., \& Liu, K. H. (2013). User requirements of social media for the elderly: a case study in Taiwan. Behaviour \& Information Technology, 32(9), 920-937.

Davis, F. (1989). Perceived usefulness, perceived ease of use, and user acceptance of information technology. MIS Quarterly, 13(3), 319-340.

Grove, V. (2013). Facebook Home arrives in Google Play store: CNET. Retrieved April 12, 2015, from http://www.cnet.com/news/facebook-home-arrives-in-google-play-store/

Hackman, J. R. \& Oldham, G. R. (1975). Development of the job diagnostic survey. Journal of Applied Psychology, 60(2), 159-170.

Hacker, J., Wickramasinghe, N., \& Durst, C. (2017). Can Health 2.0 Address Critical Healthcare Challenges? Insights from the Case of How Online Social Networks Can Assist in Combatting the Obesity Epidemic. Australasian Journal of Information Systems, 21, 1-17.

Hendriks, P. (1999). Why share knowledge? The influence of ICT on the motivation for knowledge sharing. Knowledge and Process Management, 6(2), 91-100.

Herzberg, F. (1959). The motivation to work. New Jersey: Wiley.

Herzberg, F. (1987). One more time: How do you motivate employees? Harvard Business Review, 65(5), 5-16.

Jiang, Z., \& Benbasat, I. (2007). The effects of presentation formats and task complexity on online consumers' product understanding. MIS Quarterly, 31(3), 475-500.

Kang, Y., \& Lee, H. (2010). Understanding the role of an IT artifact in online service continuance: An extended perspective of user satisfaction. Computers in Human Behavior, 26(3), 353-364.

Kopelman, R. E. (1986). A point of view. Global Business and Organizational Excellence, 5(3), 209.

Kim, S., Kim, H., \& Han, S. (2013). A development of learning widget on m-learning and elearning environments. Behaviour \& Information Technology, 32(2), 190-202.

Krugman, H. (1965). The impact of television advertising: Learning without involvement. Public Opinion Quarterly, 29(3), 349-356.

Kwon, O., \& Wen, Y. (2010). An empirical study of the factors affecting social network service use. Computers in Human Behavior, 26(2), 254-263.

Lee, S. G., Chae, S. H., \& Cho, K. M. (2013). Drivers and inhibitors of SaaS adoption in Korea. International Journal of Information Management, 33(3), 429-440. 
Lee, S., Shin, B., \& Lee, H. G. (2009). Understanding post-adoption usage of mobile data services: The role of supplier-side variables. Journal of the Association for Information Systems, 10(12), 860-888.

Lim, W. M. (2015). Antecedents and consequences of e-shopping: an integrated model. Internet Research, 25(2), 184-217.

Lin, C., Wu, S., \& Tsai, R. (2005). Integrating perceived playfulness into expectationconfirmation model for web portal context. Information $\mathcal{E}$ Management, 42(5), 683-693.

Lin, J., \& Lu, H. (2000). Towards an understanding of the behavioral intention to use a website. International Journal of Information Management, 20(3), 197-208.

Lin, K., \& Lu, H. (2015). Predicting mobile social network acceptance based on mobile value and social influence. Internet Research, 25(1), 107-130.

Lu, Y., Zhou, T., \& Wang, B. (2009). Exploring Chinese users' acceptance of instant messaging using the theory of planned behavior, the technology acceptance model, and the flow theory. Computers in Human Behavior, 25(1), 29-39.

Luarn, P., \& Chiu, Y. (2015). Key variables to predict tie strength on social network sites. Internet Research, 25(2), 218-238.

Maidani, E. A. (1991). Comparative study of Herzberg's two-factor theory of job satisfaction among public and private sectors. Public Personnel Management, 20(4), 441-448.

Maddox, R. N. (1981). Two-factor theory and consumer satisfaction: Replication and extension. Journal of Consumer Research, 8(1), 97-102.

Moon, J., \& Kim, Y. (2001). Extending the TAM for a world-wide-web context. Information $\mathcal{E}$ Management, 38(4), 217-230.

Mouakket, S. (2015). Factors influencing continuance intention to use social network sites: The Facebook case. Computers in Human Behavior, 53, 102-110.

Murphy, G.C. \& Fraser, B.J. (1978). Intuitive-theoretical scales of content and context satisfaction. Personnel Psychology, 31(3), 485-494.

Nguyen, H. Q., Johnson, B., \& Hackett, M. (2003). Testing Applications on the Web: Test Planning for Mobile and Internet-based Systems Paperback. John Wiley \& Sons, UK, London.

Nielsen. (2012). Social media report 2012: Social media comes of age. Nielsen Report. Retrieved April 20, 2015, from http://www.nielsen.com/us/en/insights/news/2012/social-mediareport-2012-social-media-comes-of-age.html

Park, N., Roman, R., Lee, S., \& Chung, J. E. (2009). User acceptance of a digital library system in developing countries: An application of the Technology Acceptance Model. International journal of information management, 29(3), 196-209.

Pizzutti dos Santos, C., \& Basso, K. (2012). Price unfairness: the indirect effect on switching and negative word-of-mouth. Journal of Product $\mathcal{E}$ Brand Management, 21(7), 547-557.

Pogue, D. (2013). Facebook Grabs for Your Phone. What Gives? The New York Times. Retrieved April 9, 2015, from http://www.nytimes.com/2013/04/11/technology/personaltech/facebooksgrab-for-your-phone-what-gives.html? $\mathrm{r}=0$ 
Poppleton, P. (1998). Teacher professional satisfaction: Its implications for secondary education and teacher education. Cambridge Journal of Education, 18(1), 5-16.

Rantz, M. J., Scott, J., \& Porter, R. (1996). Employee motivation: new perspectives of the ageold challenge of work motivation. Nursing Forum, 31(3), 29-36.

Rauniar, R., Rawski, G., Yang, J., \& Johnson, B. (2014). Technology acceptance model (TAM) and social media usage: an empirical study on Facebook. Journal of Enterprise Information Management, 27(1), 6-30.

Santosa, P., Wei, K., \& Chan, H. (2005). User involvement and user satisfaction with information-seeking activity. European Journal of Information Systems, 14(4), 361-370.

Schwab, D. P., \& Cummings, L. L. (1970). Theories of performance and satisfaction: A review. Industrial Relations - A Journal of Economy and Society, 9(4), 408-430.

Shiau, W., \& Luo, M. (2013). Continuance intention of blog users: The impact of perceived enjoyment, habit, user involvement and blog time. Behavior $\mathcal{E}$ Information Technology, $32(6), 570-583$.

Sledgianowski, D., \& Kulviwat, S. (2009). Using social network sites: The effects of playfulness, critical mass and trust in a hedonic context. Journal of Computer Information Systems, 49(4), 74-83.

Soliman, H. M. (1970). Motivation-Hygiene theory of job attitudes: An empirical investigation and attempt to reconcile both the one and two-factor theories of job attitudes. Journal of Applied Psychology, 54, 452-461.

Statista. (2017). Penetration of leading social networks in Taiwan as of 4th quarter 2016. Retrieved December 12, 2017, from https://www.statista.com/statistics/295611/taiwansocial-network-penetration/

Stern, J. (2013). Facebook Home and HTC First Review: A Nice Place to Visit, but Not Quite Home, abc News. Retrieved April 9, 2013, from http://abcnews.go.com/Technology/facebook-home-htc-review-facebooktakes-face-phone/story?id=18916810

Tao, Z. (2011). Understanding online community user participation: A social influence perspective. Internet Research, 21(1), 67-81.

Tuten, T.L. \& August, R.A. (1998). Understanding consumer satisfaction in services settings:A bidimensional model of service strategies. Journal of Social Behavior and Personality, 13(3), 553.

Tuch, A. N., \& Hornbæk, K. (2015). Does Herzberg's notion of hygienes and motivators apply to user experience? ACM Transactions on Computer-Human Interaction (TOCHI), 22(4), 16

User interface flow diagrams (UI storyboards) (2017). An Agile Introduction, Retrieved December 8, 2017, from http://agilemodeling.com/artifacts/uiFlowDiagram.htm

Vansteenkiste, M., Simons, J., Lens, W., Sheldon, K. M., \& Deci, E. L. (2004). Motivating learning, performance, and persistence: the synergistic effects of intrinsic goal contents and autonomy-supportive contexts. Journal of Personality and Social Psychology, 87(2), 246260. 
Wang, X. (2016). People's motivation to participate in social network sites, subsequent behaviours, and situation self-awareness following a crisis: Evidence from the MH370 flight incident. Australasian Journal of Information Systems, 20, 1-22.

Wei, P., \& Lu, H. (2014). Why do people play mobile social games? An examination of network externalities and of uses and gratifications. Internet Research, 24(3), 313-331.

Wiseman, R. M., Cuevas-Rodríguez, G., \& Gomez-Mejia, L. R. (2012). Towards a social theory of agency. Journal of Management Studies, 49(1), 202-222.

Whitsett, D. A. \& Winslow, E. K. (1967). An analysis of studies critical of the motivator-hygiene theory. Personnel Psychology, 20(4), 391-416.

Wu, L. L., Chuang, Y. L., \& Chen, P. Y. (2008). Motivation for using search engines: A twofactor model, Journal of the American Society for Information Science and Technology, 59(11), 1829-1840.

Yen, D., Wu, C., Cheng, F., \& Huang, Y. (2010). Determinants of users' intention to adopt wireless technology: An empirical study by integrating TTF with TAM. Computers in Human Behavior, 26(5), 906-915.

Zaichkowsky, J. (1994). Research notes: The personal involvement inventory: Reduction, revision, and application to advertising. Journal of Advertising, 23(4), 59-70.

Zhang, P., \& von Dran, G. (2000). Satisfiers and dissatisfiers: A two-factor model for website design and evaluation. Journal of the American Society for Information Science and Technology, 51(14), 1253-1268. 


\section{Appendix 1. Study 1 question lists}

\begin{tabular}{|c|c|c|}
\hline Category & Questionnaires & Name \\
\hline \multirow{15}{*}{$\begin{array}{l}\mathcal{C} \\
\stackrel{0}{\mathscr{m}} \\
\stackrel{\mathscr{E}}{E}\end{array}$} & 1. The information can be seen immediately & See information immediately \\
\hline & $\begin{array}{l}\text { 2. Users can arrange the layout of information context on } \\
\text { their timelines page. (e.g. based on the updating status, best } \\
\text { nearby, the friends nearby me) }\end{array}$ & $\begin{array}{l}\text { Arrange layout on timelines } \\
\text { page }\end{array}$ \\
\hline & \begin{tabular}{|l|} 
3. Users can customize their background pages \\
\end{tabular} & Background customization \\
\hline & 4. Have a user guide while first using the application & User guide support \\
\hline & 5. Swipe pages smoothly & Swipe pages \\
\hline & 6. The latest article could be placed on the top of timeline & The latest articles on the top \\
\hline & \begin{tabular}{|l|} 
7. Go back the previous page \\
\end{tabular} & Go back \\
\hline & 8. Go back to home page & Go back home \\
\hline & 9. Have a loading status icon & Loading status icon \\
\hline & $\begin{array}{l}\text { 10. The system is stable while operation (e.g. click the link } \\
\text { button will not jump back to home without warning) }\end{array}$ & Stability while in operation \\
\hline & $\begin{array}{l}\text { 11. Have diverse languages version (e.g. Chinese, } \\
\text { English, Japanese) }\end{array}$ & Multiple languages selection \\
\hline & 12. The information could be saved on the timeline & Save information \\
\hline & 13. Have a link function for user to click accurately & Click link accurately \\
\hline & 14. Privacy setting function & Privacy setting \\
\hline & $\begin{array}{l}\text { 15. Have permission to restrict the reading authority based } \\
\text { on groups }\end{array}$ & $\begin{array}{l}\text { Authority for restricting } \\
\text { reading articles }\end{array}$ \\
\hline \multirow{11}{*}{ 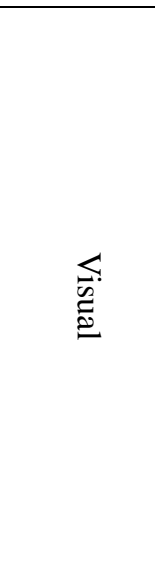 } & 16. Have a consistency design layout & Consistency of layout \\
\hline & 17. Have a consistency icon design & Consistency of icons \\
\hline & 18. Dynamic font (e.g. twinkle text) & Dynamic font \\
\hline & \begin{tabular}{|l|} 
19. Have a consistency font for wording \\
\end{tabular} & Consistency of font \\
\hline & 20. Have the same space & Consistency of space \\
\hline & 21. Have a consistency visual style & Consistency visual \\
\hline & 22. Have a colourful visual design & Colourful visual design \\
\hline & $\begin{array}{l}\text { 23. The main function buttons are designed on the top of } \\
\text { home page }\end{array}$ & Main functions on top of home \\
\hline & $\begin{array}{l}\text { 24. The main function buttons are designed on the bottom of } \\
\text { home page }\end{array}$ & $\begin{array}{l}\text { Main functions on bottom of } \\
\text { home }\end{array}$ \\
\hline & 25. The interface of albums can be swiped for reading & Swipe while reading albums \\
\hline & $\begin{array}{l}\text { 26. Have clear icons to identify (e.g., camera icon means } \\
\text { photography or take a picture) }\end{array}$ & Clear icons to identify \\
\hline \multirow{15}{*}{ 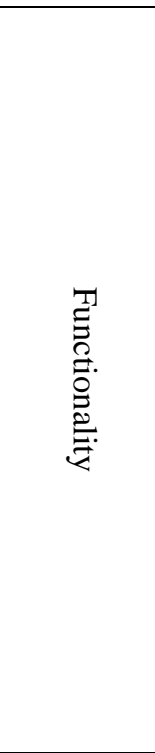 } & 27. Share location & Share location \\
\hline & 28. Giving virtual gifts & Virtual gifts \\
\hline & 29. Photography & Photography \\
\hline & 30. Edit photos & Edit photos \\
\hline & $\begin{array}{l}\begin{array}{l}\text { 31. Save photos (e.g., users can save the favourite photos to } \\
\text { their folders) }\end{array} \\
\end{array}$ & Save photos \\
\hline & 32. Tag friends & Tag friends \\
\hline & 33. Save favourite message & Save message \\
\hline & 34. Like, +1 function & Like function \\
\hline & $\begin{array}{l}\text { 35. The home page can be sorted by diverse categories (e.g. } \\
\text { food, night market, coffee) }\end{array}$ & Sort home by categories \\
\hline & 36. Have a video call & Video call \\
\hline & 37. Have emotional icons while typing text & Emotional icon for texting \\
\hline & 38. Activities remind for birthday parties or events & Reminder alarm \\
\hline & 39. My favourite & My favourite \\
\hline & $\begin{array}{l}\text { 40. Incentive mechanisms (e.g. have a visual reward while } \\
\text { sharing location) }\end{array}$ & Incentive mechanisms \\
\hline & 41. Search function & Search function \\
\hline
\end{tabular}




\section{Appendix 2. Task lists}

\begin{tabular}{|c|c|c|}
\hline Function & Task description & Purpose \\
\hline Dynamic font & $\begin{array}{l}\text { Type 'great' then click dynamic font button, select the } \\
\text { colour as red, and add a food photo before posting. } \\
\text { Finally, go back to home page. }\end{array}$ & $\begin{array}{l}\text { To investigate users' visual feeling } \\
\text { with dynamic font interface. }\end{array}$ \\
\hline Video call & $\begin{array}{l}\text { Looking for Andy Liu and Judy Lu from friend lists } \\
\text { first then select the video call button. After finishing } \\
\text { video call, press the end button to hang up the phone. } \\
\text { Finally, go back to home page. }\end{array}$ & $\begin{array}{l}\text { To investigate if the video call } \\
\text { could enhance users' intention to } \\
\text { revisit the SNS app. }\end{array}$ \\
\hline My favourite & $\begin{array}{l}\text { Scroll up and down to review friends' posts and find a } \\
\text { post from Wang Hsiao Ming. Add this post into my } \\
\text { favourite. Then go back to home page to find the post } \\
\text { which you just saved it, then share this post to your } \\
\text { friends as Ben Yang, Candy and Linda. Finally, go } \\
\text { back to home page. }\end{array}$ & $\begin{array}{l}\text { To extend the function of to do list } \\
\text { idea for investigating whether the } \\
\text { multiple interaction functions could } \\
\text { simulate users' behavioural } \\
\text { intention to revisit the SNS app. }\end{array}$ \\
\hline $\begin{array}{l}\text { Incentive } \\
\text { mechanisms }\end{array}$ & $\begin{array}{l}\text { Click 'share location' button to share the current } \\
\text { location as the northeast coast coffee shop. Follow by } \\
\text { typing 'great' and pick up a coffee photography from } \\
\text { phone library before posting. When finish posting, the } \\
\text { SNS app system will send a trophy to you, then click } \\
\text { this trophy directly to link to your personal award } \\
\text { record page. Finally, go back to home page. }\end{array}$ & $\begin{array}{l}\text { To investigate if users can be } \\
\text { simulated by sending reward } \\
\text { message for improving their feeling } \\
\text { of PP for enhancing their willing to } \\
\text { share information and post articles } \\
\text { with their peers. }\end{array}$ \\
\hline Virtual gifts & $\begin{array}{l}\text { Scroll up and down for reading friends' posts and press } \\
\text { 'AWESOME' button for Luca Wu's post, and leave a } \\
\text { message as 'great' then select a gift as a cake to her. } \\
\text { Finally, go back to the home page. }\end{array}$ & $\begin{array}{l}\text { To enhance the usefulness function } \\
\text { for users for increasing their BI for } \\
\text { revisiting this SNS app. }\end{array}$ \\
\hline
\end{tabular}

Note: the above questioners all includes four options for participates to choose, they are Basic function (if not have, will complain), Additional function (if have, will satisfy), Unclear basic or additional function and Unclear wording. 


\section{Appendix 3. Study 2 question lists}

\section{Involvement level question lists}

\begin{tabular}{|l|}
\hline Questions: \\
\hline 1. Facebook is important to me \\
\hline 2. It is interesting to use Facebook \\
\hline 3. All social activities on Facebook are relevant to my life \\
\hline 4. I am excited about using Facebook \\
\hline 5. Facebook means a lot to me \\
\hline 6. I think Facebook appealing to me \\
\hline 7. I feel fascinating with Facebook \\
\hline 8. The relationship with my friends on Facebook is valuable \\
\hline 9. I am involving on Facebook and would like to share my status with friends \\
\hline 10. I need Facebook \\
\hline
\end{tabular}

\section{TAM question lists ${ }^{1}$}

\section{Questions:}

1. Using this social networking APP improves my relationship quality with my friends

2. Using this social networking APP improves the performance of my social life

3. Using this social networking APP helps me to improve the critical part of interaction with my friends in physical life

4. Using this social networking APP improves my efficiency in sharing information and connecting with others

5. Using this social networking APP enables me to acquire more information and know more people

6. Using this social networking APP enables me to have more useful information

7. Using this social networking APP enables me to access a lot of updated information from my friends

8. Using this social networking APP enables me to access a lot of the latest information

9. Using this social networking APP enables me to acquire high quality information

10. It will be impossible to use this social networking APP without expert help

11. Learning to operate this social networking APP is easy for me

12. It is difficult to learn how to use this social networking APP

13. I find it easy to get this social networking APP to do what I want it to do

14. It takes too long a time to learn how to use this social networking APP

15. It is easy to remember how to use this social networking APP

16. Using this social networking APP requires a lot of mental effort

\footnotetext{
${ }^{1}$ We first asked participants' perception about the use of FB app, then after participants completed the tasks with Unicorn app, we ask their perception about the use of Unicorn app.
} 
17. My interaction with this social networking APP is clear and understandable

18. It is easy for me to become skillful at using this social networking APP

19. When interacting with this social networking APP, I do not realize the time elapsed

20. When interacting with this social networking APP, I am not aware of any noise

21. When interacting with this social networking APP, I often forget the work I must do

22. Using this social networking APP gives enjoyment to me for my task

23. Using this social networking APP gives fun to me for my task

24. Using this social networking APP keeps me happy with my task

25. Using this social networking APP stimulates my curiosity

26. Using this social networking APP leads to my exploration

27. Using this social networking APP arouses my imagination

28. I will use this social networking APP on a regular basis in the future

29. I will frequently use this social networking APP in the future

30. I will strongly recommend others to use this social networking APP 


\section{Appendix 4. Reliability analysis}

\begin{tabular}{|l|l|l|}
\hline Category & Item & Cronbach's alpha \\
\hline MF social networking APP & 9 & 0.80 \\
\hline PU & 9 & 0.91 \\
\hline PEOU & 9 & 0.85 \\
\hline PP & 3 & 0.89 \\
\hline BI & \multicolumn{2}{|l|}{} \\
\hline None MF social networking APP & 9 & 0.85 \\
\hline PU & 9 & 0.88 \\
\hline PEOU & 9 & 0.88 \\
\hline PP & 3 & 0.87 \\
\hline BI & 10 & 0.86 \\
\hline The Involvement Level of SNS & \multicolumn{1}{|l|}{} \\
\hline
\end{tabular}

Copyright: () 2018 Huang, Yang \& Chen. This is an open-access article distributed under the terms of the Creative Commons Attribution-NonCommercial 3.0 Australia License, which permits non-commercial use, distribution, and reproduction in any medium, provided the original author and AJIS are credited.

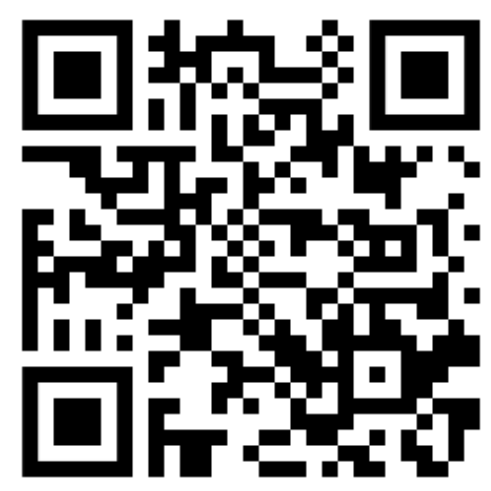

